\title{
O PROCESSO DE AFIRMAÇÃO DOS DIREITOS HUMANOS EM FACE DO CONCEITO CONSTITUCIONAL DE DIREITO AMBIENTAL
}

\author{
THE AFFIRMATION PROCESS OF HUMAN RIGHTS IN FACE OF THE \\ CONSTITUTIONAL CONCEPT OF ENVIRONMENTAL LAW
}

\begin{abstract}
Celso Pacheco Fiorillo
Professor livre-docente em Direito Ambiental. Doutor e Mestre em Direito das Relações Sociais pela Pontifícia Universidade Católica de São Paulo (PUC/SP). Professor do Programa de Mestrado em Direito da Universidade Nove de Julho (UNINOVE). Coordenador e professor do Curso de Especialização de Direito Ambiental da Escola Superior de Advocacia da Ordem dos Advogados do Brasil - Seção São Paulo. Professor da Escola de Magistratura do Tribunal Regional Federal da $3^{\circ}$ Região. Professor da Escola Nacional de Formação e Aperfeiçoamento de Magistrados (ENFAM). Advogado. E-mail: capfiorillo@terra.com.br

\section{Renata Marques Ferreira}

Pós-doutora em Engenharia Ambiental e Hidráulica (Contaminação e Remediação de Solos) pela Escola Politécnica da Universidade de São Paulo (POLI-USP). Doutora e

Mestra em Direito das Relações Sociais pela PUC/SP. Professora do Programa de Mestrado em Saúde Ambiental das Faculdades Metropolitanas Unidas (FMU). Professora das Faculdades Integradas Rio Branco (Fundação Rotary). E-mail: renferreira@uol.com.br
\end{abstract}

Recebido em: 01/11/2016

Aprovado em: 16/07/2017

Doi: $10.5585 /$ rdb.v17i7.527

RESUMO: O conceito de direitos humanos está relacionado historicamente e estruturalmente aos direitos da pessoa humana importando então estabelecer um conceito possível de referida expressão em face de alguns critérios que indicam uma visão panorâmica a respeito da concepção de pessoa humana. Referidos critérios influenciam evidentemente a interpretação do sistema de direito constitucional brasileiro no que se refere à positivação dos direitos humanos particularmente em face de se assegurar concretamente, no plano normativo constitucional, a efetividade do denominado piso vital mínimo indicado no art. $6^{\circ}$ da Constituição Federal, a saber, observar o direito ambiental constitucional assegurando a dignidade da pessoa humana. $\mathrm{O}$ direito a integridade do meio ambiente, em face de sua conceituação constitucional (meio ambiente cultural, meio ambiente artificial, meio ambiente do trabalho e meio ambiente natural) constitui prerrogativa jurídica de titularidade coletiva, refletindo, dentro do processo de afirmação dos direitos humanos a expressão significativa de um poder deferido, não ao indivíduo identificado em sua singularidade, mas, num sentido verdadeiramente mais abrangente, atribuído à própria coletividade social conforme já proclamado pelo STF na ADI 3540.

Palavras-chave: Direitos Humanos. Direito Ambiental Constitucional. Dignidade da Pessoa Humana. Meio Ambiente. 


\begin{abstract}
The concept of human rights is historically and structurally related to the rights of the human person then importing establish a possible concept of that expression in the face of some criteria that indicate an overview about the concept of the human person. These criteria clearly influence the interpretation of the Brazilian constitutional law system as regards the positivization of human rights particularly in the face to ensure concretely, the constitutional normative level, the effectiveness of the so-called minimum living floor indicated in art. 6 of the Brazilian Federal Constitution, namely, to observe the constitutional environmental law ensuring the dignity of the human person. The right to integrity of the environment in the face of its constitutional concept (cultural environment, artificial environment, environmental work and natural environment) is legal right of collective ownership, reflecting, in the process of affirmation of human rights significant expression of a power granted, not to the individual identified in its uniqueness, but in a truly comprehensive way, assigned to own social collectivity as already proclaimed by the Supreme Court in ADI 3540.
\end{abstract}

Keywords: Human Rights. Constitutional Environmental Law. Dignity of Human Person. Environment.

SUMÁRIO: Introdução. 1. Conceito possível de direitos humanos. 2. Conceito possível de pessoa humana. 3. Os direitos humanos como direitos da pessoa humana e sua positivação no plano constitucional brasileiro: a dignidade da pessoa humana e o piso vital mínimo. 4. O piso vital mínimo como direito humano: o direito ambiental constitucional assegurando a dignidade da pessoa humana. 5. Os quatro significativos aspectos do direito ambiental constitucional assegurando a dignidade da pessoa humana como direitos humanos básicos e sua interpretação por parte do Supremo Tribunal Federal. Conclusão. Referências Bibliográficas.

\title{
INTRODUÇÃO
}

A afirmação histórica dos direitos humanos é parte de um processo de desenvolvimento e de evolução gradual do indivíduo, enquanto membro de uma determinada sociedade. Ao ocorrer uma série de quebras de paradigmas de valores sociais, a sociedade passa a ansiar pela concretização e pela efetivação desses referidos valores por meio de produção normativa. Quando da Revolução Francesa, estabeleceu-se alguns desses valores sociais almejados pela sociedade, quais sejam: a liberdade, a igualdade e a fraternidade. E esses valores, consagrados ao longo do tempo, inserem-se no processo de dinamogenesis dos direitos humanos.

Cada um desses valores está enquadrado nas chamadas gerações dos direitos humanos. Se a liberdade integra a primeira geração de direitos humanos; a igualdade faz parte da segunda geração. Se a liberdade está voltada a uma perspectiva liberal, no sentido de liberdade em sentido amplo (liberdade de expressão, liberdade de pensamento, liberdade religiosa, dentre outros); a igualdade volta-se a uma perspectiva social, pautada por ações positivas por parte do Estado de modo que a liberdade passa a ter certas restrições (como por exemplo, a função social do contrato, a função social da propriedade, etc.).

Por fim, a fraternidade, direito de terceira geração, tem relação direta aos direitos difusos, nas quais não há um destinatário específico, senão a coletividade e cuja natureza é indivisível. Para os fins do presente artigo, o direito ao meio ambiente sustentável (ou saudável), em todas as suas vertentes (ou modalidades), é o que mais nos interessa. Sã eles: (i) o meio ambiente cultural; (ii) o meio ambiente artificial; (iii) o meio ambiente do trabalho e (iv) o meio ambiente natural.

A Constituição Federal de 1988 buscou, ao longo de sua existência, internalizar os valores advindos da sociedade internacional. Em outras palavras, buscou efetivar e concretizar os direitos humanos no ordenamento jurídico brasileiro, notadamente em nosso mais importante 
documento jurídico: a Carta Magna. O objetivo, parece-nos claro, é assegurar concretamente a efetividade do denominado piso vital mínimo, consoante artigo $6^{0^{1}}$, para fins de assegurar a dignidade da pessoa humana.

$\mathrm{O}$ direito à integridade do meio ambiente constitui prerrogativa jurídica de titularidade coletiva, direitos de terceira geração, refletindo, dentro do processo de afirmação dos direitos humanos, a expressão significativa de um poder deferido, não ao indivíduo identificado em sua singularidade, mas, num sentido verdadeiramente mais abrangente, atribuído à própria coletividade social conforme já proclamado pelo STF na ADI 3540.

\section{CONCEITO POSSÍVEL DE DIREITOS HUMANOS}

Um dos possíveis conceitos de direitos humanos ${ }^{2}$ está associado historicamente à Declaração dos Direitos do Homem e do Cidadão de $1789^{3}$. Expressão de um momento ${ }^{4}$, como explica Vovelle, "trata-se de documento fundamental oriundo da Revolução Francesa, oportunidade em que os representantes do povo francês reunidos em Assembleia Nacional, tendo em vista que a ignorância, o esquecimento ou o desprezo dos direitos do homem são as únicas causas dos males públicos e da corrupção dos Governos" resolveram:

declarar solenemente os direitos naturais, inalienáveis e sagrados do homem, a fim de que esta declaração, sempre presente em todos os membros do corpo social, lhes lembre permanentemente seus direitos e seus deveres; a fim de que os atos do Poder Legislativo e do Poder Executivo, podendo ser a qualquer momento comparados com a finalidade de toda a instituição política, sejam por isso mais respeitados; a fim de que as reivindicações dos cidadãos, doravante fundadas em princípios simples e incontestáveis, se dirijam sempre à conservação da Constituição e à felicidade geral a Declaração dos Direitos do Homem e do Cidadão tinha como objetivo inequívoco reconhecer e declarar por escrito sob a égide do Ser Supremo dezessete direitos do Homem e do Cidadão.

Ao pretender "declarar solenemente os direitos naturais, inalienáveis e sagrados do homem" a Declaração dos Direitos do Homem e do Cidadão de 1789 evidentemente apontava uma visão enquadrada dentro de uma concepção que iria ser mais tarde modificada. Como bem explica Caenegem ${ }^{5}$ :

formou-se na era moderna uma nova concepção do direito natural (...) que concebia o direito natural como um corpo de princípios básicos dos quais o direito positivo deveria ser diretamente derivado: era um direito natural aplicado

\footnotetext{
${ }^{1}$ Dispõe referido artigo que: "são direitos sociais a educação, a saúde, a alimentação, o trabalho, a moradia, o transporte, o lazer, a segurança, a previdência social, a proteção à maternidade e à infância, a assistência aos desamparados, na forma desta Constituição".

${ }^{2}$ Para Cranston "direitos humanos é uma expressão do século XX para o que foi tradicionalmente conhecido como direitos naturais, ou, numa frase mais estimulante, os direitos do homem" (Cranston, Maurice. O que são direitos humanos? São Paulo/Rio de Janeiro: Difel, 1979, p. 1.

${ }^{3} \mathrm{Na}$ realidade, como observa Matteucci "a Déclaration tinha dois grandes precedentes: os Bills of rights de muitas colônia americanas que se rebelaram em 1776 contra o domínio da Inglaterra e o Bill of right inglês, que consagrava a gloriosa revolução de 1689 (BOBBIO, Norberto; MATTEUCCI, Nicola; PASQUINO, Gianfranco. Dicionário de Política. 13.ed. Volume 1 Brasília: Editora Universidade de Brasília, 2010, p. 352).

4 "Tradicionalmente, à Declaração de 1789 opõe-se a que foi redigida no início do Verão de 1793 como preambulo á nova Constituição que se seguiu à queda da monarquia e da qual se sublinham as "antecipações", como a de 1795, que abre a Constituição do ano III, expressão de um retorno à ordem, insistindo nos deveres e pondo em suspenso parte dos avanços precedentes" (VOVELLE, Michel. A Revolução Francesa 1789-1799. 70.ed. Lisboa: Portugal, 2007, pp. 68-70).

${ }^{5}$ CAENEGEM, R. C. van. Uma introdução histórica ao direito privado. São Paulo: Martins Fontes, 1995, p.120.

Revista de Direito Brasileira | São Paulo, SP | v. 17 | n. 7 | p. 191 - 202 | Mai./Ago. 2017
} 
(...) através do estudo racional e da crítica da natureza humana, os autores dessa escola procuravam princípios evidentes e axiomáticos, dos quais pudessem deduzir todos os outros more geométrico. $O$ nome direito da razão (vernunftrecht) ${ }^{6}$ é, portanto, mais adequado do que "direito natural".

De qualquer forma tratava-se, na verdade e em síntese, conforme bem observa Matteucci ${ }^{7}$, de "consagrar as vitórias do cidadão sobre o poder" através da promulgação de um texto escrito contendo uma declaração dos Direitos Humanos e de cidadania. Assim assegurar diretos "do homem" e do "cidadão" foi, como dissemos anteriormente, a razão de ser da elaboração de um texto destinado a assegurar garantias formais em face do poder constituído dentro de um específico contexto histórico de uma nova concepção do direito natural que iria acabar no final do século $\mathrm{XIX}^{8}$.

No século $\mathrm{XX}$, considerando que o reconhecimento da dignidade inerente a todos os membros da família humana e de seus direitos iguais e inalienáveis é o fundamento da liberdade, da justiça e da paz no mundo, a Assembleia Geral das Nações Unidas entendeu por bem proclamar em 10 de dezembro de 1948 uma Declaração Universal dos Direitos Humanos contendo 30 artigos destinados fundamentalmente a estabelecer que "toda pessoa tem capacidade para gozar os direitos e as liberdades estabelecidas nesta Declaração, sem distinção de qualquer espécie, seja de raça, cor, sexo, língua, religião, opinião política ou de outra natureza, origem nacional ou social, riqueza, nascimento, ou qualquer outra condição" 9 ".

Destarte seja em face do homem, ou inerente à família humana ou mesmo destinado a toda e qualquer pessoa, o conceito de Direitos Humanos, ao longo da história, sempre esteve intrinsecamente relacionado ao conceito de pessoa humana. Segundo Perez Luño ${ }^{10}$, os direitos humanos consistiriam em um:

conjunto de faculdades e instituições que, em cada momento histórico, concretizam as exigências da dignidade, da liberdade e da igualdade humanas, as quais devem ser reconhecidas positivamente pelos ordenamentos jurídicos em nível nacional e internacional.

Daí ser absolutamente razoável concluir que o conceito de direitos humanos está relacionado estruturalmente aos direitos da pessoa humana. Importaria então tentar estabelecer um conceito possível de pessoa humana. Senão vejamos.

\footnotetext{
6 "O jusracionalismo não constitui senão um curto capítulo histórico das muito mais vastas manifestações do jusnaturalismo" observa Wieacker. "O próprio direito natural é, um por um lado, uma questão permanente do homem teórico cerca do seu lugar na sociedade e, como tal, uma filosofia social; mas, por outro lado, é uma traição cultural que se mantem desde os inícios da filosofia helenística até a actualidade" (WIEACKER, Franz. História do Direito Privado. 2.ed. Lisboa: Fundação Calouste Gulbenkian, 1967, p. 280.

${ }^{7}$ BOBBIO, Norberto; MATTEUCCI, Nicola; PASQUINO, Gianfranco. Dicionário de Política. 13.ed. Volume 1 Brasília: Editora Universidade de Brasília, 2010, p. 352.

8 Conforme lembra R.C.van Caenegem "o próprio direito natural, embora estivesse muito em voga no Iluminismo, tinha pouca vida à sua frente. No começo do século XIX, já perdera toda a sua importância verdadeira como princípio orientador e como fonte de inspiração para o direito". Como bem indica o historiador belga "uma vez que os códigos revolucionários foram promulgados e a ordem civil do século XIX foi assegurada, o direito natural passou a ser apenas uma fonte suspeita de crítica". E conclui: "Em meados do século XIX, Windscheid observou: "Der Traum des Naturrechts ist ausgeträumt" ("o sonho do direito natural acabou"). O direito natural agora não passava de um tema puramente acadêmico sem significado prático" (CAENEGEM, 1995, p. 197-198.)

9 A Declaração Universal dos Direitos Humanos foi adotada e proclamada pela Resolução no 217 A (III) da Assembleia Geral das Nações Unidas em 10 de dezembro de 1948 e foi assinada pelo Brasil na mesma data.

${ }^{10}$ PÉREZ-LUÑO, Antonio Enrique. Derechos Humanos, Estado de Derecho y Constitución. 2.ed. Madrid: Technos, 1999, p. 43.
}

Revista de Direito Brasileira | São Paulo, SP | v. 17 | n. 7 | p. 191 - 202 | Mai./Ago. 2017 


\section{CONCEITO POSSÍVEL DE PESSOA HUMANA}

Já no final do século XX, explica Celso Fiorillo" que a palavra "humano" (do latim humanu), é entendida como "pertencente ou relativo ao homem: natureza humana; gênero humano". Por sua vez, o termo "pessoa" (do latim persona), "é compreendido como homem ou mulher" $"$.

De qualquer forma, embora o grupo dos hominídeos tenha aparecido, conforme apontam os cientistas, há aproximadamente 5 milhões de anos, sendo o primeiro testemunho indiscutível o esqueleto quase completo de "Lucy", encontrado em 1974 na Etiópia e datado de 3,5 milhões de anos, e, levando-se em conta a recente descoberta do paleontologista britânico Ronald J. Clarke, que encontrou na caverna de Sterkfontein (África do Sul) no ano de 1998 um hominídeo de 3,6 milhões de anos, conhecido por seu número de catálogo (STW573) ou pelo apelido de "Pezinho" (Little Foot), entende-se como certo pela ciência que o gênero Homo teria surgido há aproximadamente 2 milhões de anos.

O gênero Homo ${ }^{13}$ começa com o Homo habilis, capaz de fabricar ferramentas simples. Todavia, o Homo ou Pithecanthropus erectus (homem ereto) ou "Homem de Java", de 1,5 milhão de anos, não está associado a ferramentas. O "Homem de Neanderthal" (Homo neanderthalensis) apareceu há aproximadamente 200 mil anos e o "Homem de Cro-Magnon", primeiro verdadeiro Homo sapiens, há 30 mil anos. O Pleistoceno ou era quaternária corresponde ao aparecimento do homem.

A evolução do homem manifesta-se pela sua aptidão em fabricar ferramentas ("indústria") cada vez mais aperfeiçoadas. No Paleolítico, fazia seixos lascados e, depois, sílex cada vez mais sofisticados até que, no Paleolítico mais recente, já produzia finas pontas de flechas. Nas épocas do Mesolítico e, principalmente, do Neolítico, desenvolveu-se a Idade da Pedra Polida, seguida pelo uso dos metais a partir das Idades do Cobre, do Bronze e, finalmente, do Ferro.

Descobertas fundamentais e novos comportamentos marcam a progressão do homem para a civilização, a saber: (i) o fogo pelo Homem de Pequim, Homo ou Sinanthropus pekinensis, há 500 mil anos; (ii) as sepulturas e, portanto, as primeiras reflexões metafísicas, no Homem de Neanderthal, há 50 mil anos; (iii) pinturas rupestres e esculturas simbólicas (deusa da fecundidade), ou seja, arte, no Homem de Cro-Magnon; (iv) agricultura e pecuária desde o Mesolítico, promovendo a passagem progressiva de uma sociedade de caçadores para uma sociedade de produtores; (v) monumentos megalíticos (dólmen, menir) no Neolítico; e (vi) a escrita. Esses progressos apareceram em várias regiões do mundo e espalharam-se lentamente.

Na obra "Princípios Constitucionais do Direito da Sociedade da Informação - A Tutela Jurídica do Meio Ambiente Digital"14, encontramos também algumas informações relevantes relacionadas ao tema no campo jurídico, a saber, dentre outras, a interpretação de Maria Helena Diniz, que, ao trazer à colação Washington de Barros Monteiro, explica que o vocábulo "pessoa" é oriundo do latim persona, que, adaptado à linguagem teatral, designava máscara. Isso seria assim porque persona advinha do verbo personare, que significava ecoar, ressoar, de forma que a máscara era uma persona que fazia ressoar, mais intensamente, a voz da pessoa por ela ocultada.

\footnotetext{
${ }^{11}$ FIORILLO, Celso Antonio. O direito de antena em face do direito ambiental no Brasil. São Paulo: Saraiva, 2000, passim.

${ }^{12}$ FIORILLO, Celso Antonio. O direito de antena em face do direito ambiental no Brasil. São Paulo: Saraiva, 2000, passim.

A A esse respeito, ver: Disponível em: 〈http://www.museunacional.ufrj.br/guiaMN/Guia/paginas/2/14hominideos.htm〉. Acesso em 14 de julho de 2017.

${ }^{14}$ Para melhor aprofundamento, ver: FIORILLO, Celso Antonio. $O$ direito de antena em face do direito ambiental no Brasil. São Paulo: Saraiva, 2000.
}

Revista de Direito Brasileira | São Paulo, SP | v. 17 | n. 7 | p. 191 - 202 | Mai./Ago. 2017 
Mais tarde persona passou a exprimir a própria atuação do papel representado pelo ator e, por fim, completando esse ciclo evolutivo, a indicar o próprio homem que representava o papel. Passaria, então, a ter três acepções:

a) a vulgar, em que a pessoa seria sinônimo de ser humano; porém, não se poderia tomar com precisão tal assertiva, ante a existência de instituições que têm direitos e deveres, sendo, por isso, consideradas como pessoas, e devido ao fato de que já existiram seres humanos que não eram considerados pessoas, como os escravos. Em Roma estes eram tratados como animais, coisa (res), objeto de direito subjetivo, sendo certo que sua condição jurídica veio a perdurar por toda a evolução do direito romano, mas com atenuações gradativas sem que se chegasse a modificar lhes a condição jurídica antes mencionada. Daí a ordem jurídica romana não reconhecer a todo e qualquer homem a qualidade de sujeito de direitos, uma vez que o escravo, como afirmado, não a possuía, sendo considerado objeto de direitos. Jean Sirinelli entende, por seu turno, excessivo afirmar que a instituição da escravatura definiria por si só toda a civilização antiga, "mas é preciso reconhecer que o seu papel é ao mesmo tempo considerável e oculto: considerável porque a escravatura é uma das condições da vida material, decorrente da vida política; oculto, porque, por assim dizer, nunca é objecto de exame e não constitui um problema político em si próprio vez que a condição concreta dos escravos pôde variar consideravelmente sendo possível que se humanizasse seu estatuto e aumentasse a proteção que lhes era dispensada" ${ }^{\text {" }}$. Na verdade, explica o mestre de grego na Escola Normal Superior da França, os escravos sempre se conservaram fora dos limites da reflexão política, tanto que Aristóteles, quando se ocupa desse assunto, "é apenas para o iludir, dividindo-o em dois problemas distintos".

a) Para ele, o escravo é uma "propriedade instrumental provida de alma. Todos os seres desde o primeiro instante do seu nascimento são, por assim dizer, marcados pela natureza, uns para comandar, outros para obedecer. Considerado do ponto de vista da natureza, o escravo é para o senhor aquilo que o corpo é para a alma. Todos aqueles que só têm para oferecer o uso do corpo e os seus membros estão condenados pela natureza à escravatura; é melhor para eles servir do que serem abandonados a si próprios. Em resumo, é naturalmente escravo todo aquele que tem tão pouca alma e tão poucas qualidades que se sujeita a colocar-se na dependência de outrem" 16

b) a filosófica, segundo a qual a pessoa é o ente, dotado de razão, que realiza um fim moral e exerce seus atos de modo consciente. Temos destarte na cultura da chamada sociedade ocidental a palavra razão originando-se de duas fontes: do latim ratione e do grego logos. Estes vocábulos são substantivos derivados de dois verbos que têm um sentido muito parecido em latim e em grego - logos vem do verbo legein, que significa contar, reunir, juntar, calcular; ratio, do verbo reor, quer dizer contar, reunir, medir, separar, calcular. Marilena Chauí conclui que, "quando medimos, juntamos, separamos, contamos ou calculamos, estamos pensando de modo ordenado, usando a palavra para essas ações" ${ }^{\prime 7}$. Assim, logos, ratio ou razão significam pensar e falar ordenadamente, com medida e proporção, com clareza e de modo compreensível para os outros, ou seja, capacidade intelectual para pensar e exprimir-se correta e claramente, para pensar e dizer as coisas tais como são;

c) a jurídica, que considera como pessoa todo ente físico ou moral, suscetível de direitos e obrigações, sendo que, nesse sentido, seria sinônimo de sujeito de direito ou sujeito da relação jurídica.

Hans Hattenhauer ${ }^{18}$, por sua vez, ao orientar os estudiosos de direito a respeito do tema lembra, em sua obra "Conceptos fundamentales del derecho civil (tradução espanhola elaborada

\footnotetext{
${ }^{15}$ RIOUX, Jean-Pierre; SIRINELLI, Jean- François. Para uma história cultural. Lisboa: Editorial Estampa, 1998, p. 262.

${ }^{16}$ ARISTÓTELES. A Política. São Paulo: Martin Claret, 2002, p. 14.

${ }^{17}$ CHAUÍ, Marilena. Convite à Filosofia. 8.ed. São Paulo: Ática, 1997, p. 59.

18 HATTENHAUER, Hans. Conceptos fundamentales del derecho civil - introduccion histórico-dogmática, Barcelona: Ed.Ariel, 1987, p. 56.
}

Revista de Direito Brasileira | São Paulo, SP | v. 17 | n. 7 | p. 191 - 202 | Mai./Ago. 2017 
pela Ariel Derecho)", que se necesitó largo tiempo para que en la vida jurídica el concepto de persona quedase circunscrito al hombre.

O conhecido historiador e civilista catedrático da Universidade de Kiel (ChristianAlbrechts-Universität de Kiel) ressalta que:

los fundamentos se encuentran en la teología moderna, singularmente en Tomás de Aquino (1225-1274). En todas las páginas de la Biblia veían escrito los doctores de la Iglesia que el hombre es creación de Dios y que, aun cuando criatura, es, al mismo tiempo, rey y señor de la Creación. Lo que diferenciaba al hombre de su Creador era el ser creado; de las demás criaturas le diferenciaba el don divino de la razón (ratio). El hombre era el rey de la Creación y, simultáneamente, criatura como las plantas y los animales, con quienes debia compartir el espacio vital ${ }^{19}$.

Por outro lado, um dos teóricos mais importantes da naturalidade política, Santo Tomás de Aquino, conforme explica Marilena Chauíi ${ }^{20}$, salientava que, sendo o homem um animal social, a sociabilidade natural já existia no paraíso, antes da queda e da expulsão dos seres humanos. Após o pecado original, os seres humanos não perderam sua natureza sociável e, por isso, naturalmente organizaram-se em comunidades, deram-se leis e instituíram-se as relações de mando e obediência, criando o poder político.

Diferentemente de Santo Agostinho, para quem o pecado tornara o homem perverso e violento, para Santo Tomás de Aquino, os humanos perderam a inocência original, mas não a natureza que lhes fora dada por Deus. Por esse motivo, neles permaneceu o senso de justiça, entendido como o dever de dar a cada um o que lhe é devido e com ela fundaram a comunidade política. Numa exposição histórica da filosofia medieval, a obra e a importância de Santo Tomás devem ser encaradas, como ensinam Philotheus Boehner e Etienne Gilson ${ }^{21}$,

não à luz do triunfo posterior do tomismo, mas exclusivamente no ambiente histórico do século XIII. Foi a Santo Tomás que coube a empresa histórica de retificar, num sentido cristão, o aristotelismo, que corria ao lado da teologia, sem correlação orgânica com ela, e de superá-lo, de tal modo que, depois de depurado e organicamente integrado no edifício teológico, ele passasse a servir de fundamento seguro para a mesma teologia.

Daí os autores antes referidos, mestres da história do pensamento medieval, concluírem que "o que deparamos em Santo Tomás não é, pois, um aristotelismo genuíno. Na explanação dos textos tomísticos importa não perder de vista que os termos e conceitos aristotélicos devem ser interpretados à luz do pensamento de Tomás e não do de Aristóteles". ${ }^{22}$

Rosa Maria Barreto Borriello de Andrade $\mathrm{Nery}^{23}$, ao tratar da pessoa humana, sua natureza e posição jurídica, destaca Miguel Reale, na medida em que este, em sua célebre obra "Teoria tridimensional do direito", aponta a pessoa humana como o valor fonte de que emanam todos os outros valores objetivos, de natureza histórica, e o direito como dimensão da vida humana, pois o homem é "o único ente que é e deve ser", ou, por outras palavras, como "ente, cujo ser é o seu dever-ser". Conclui referida autora que:

19 . Op. Cit, p. 47.

${ }^{20}$ CHAUÍ, Marilena. Convite à Filosofia. 8.ed. São Paulo: Ática, 1997, passim.

${ }^{21}$ BOEHNER, Philotheus; GILSON, Etienne. História da Filosofia Cristã-Desde as Origens até Nicolau de Cusa. 6.ed. Petrópolis: Vozes, 1995, p. 448.

22 . Op. Cit., p. 447.

${ }^{23}$ NERY, Maria Barreto Borriello de Andrade. Pessoa Natural: sujeito de direito. Tese de Doutorado apresentada na PUC/SP sob a orientação de Celso Antonio Pacheco Fiorillo, São Paulo, 1998.

Revista de Direito Brasileira | São Paulo, SP | v. 17 | n. 7 | p. 191 - 202 | Mai./Ago. 2017 
a pessoa humana figura no Direito com atributos que a tornam especial e individual sujeito de direitos sendo que esses atributos refletem-se no sistema jurídico, de forma multifacetária. Quando vistos pelo ângulo do Direito Público, podem ou não espelhar o exercício da cidadania. Pelo aspecto do direito privado possibilitam a defesa da dignidade da pessoa humana enquanto sujeito de direitos e a identificação de objetos que respeitem à sua natureza humana.

Vimos, portanto alguns critérios que indicam uma visão panorâmica a respeito da concepção de pessoa humana. Referidos critérios influenciarem evidentemente o sistema de direito constitucional brasileiro no que se refere à positivação dos direitos humanos.

\section{OS DIREITOS HUMANOS COMO DIREITOS DA PESSOA HUMANA E SUA POSITIVAÇÃO NO PLANO CONSTITUCIONAL BRASILEIRO: A DIGNIDADE DA PESSOA HUMANA E O PISO VITAL MÍNIMO}

Consagrando as vitórias do cidadão sobre o poder, a Constituição Brasileira de 1988 estabeleceu objetivamente ser a pessoa humana "a verdadeira razão de ser de todo o sistema de direito positivo em nosso País" 24 . Isso porque os seres aglutinados em face da denominação povo passaram a possuir um direito constitucional fundamental em nosso sistema jurídico: são pessoas humanas que gozam de uma prerrogativa constitucional básica, a saber, o direito à dignidade.

A dignidade, como critério vinculado a valores imateriais culturais dos seres humanos (amor próprio, brio, honra, respeitabilidade, etc.), é assegurada como fundamento interpretativo estrutural de todo o sistema constitucional brasileiro (art. $1^{\circ}$, inciso III).

Assim, em nosso sistema de direito constitucional positivo, para que a pessoa humana possa ter efetivamente garantida sua dignidade (CF, art. 1ㅜㅡ, inciso III) necessita que lhe sejam assegurados os direitos sociais previstos no art. 6- da Carta Magna (educação, saúde, alimentação, trabalho, moradia, lazer, segurança, previdência social, proteção à maternidade e à infância e assistência aos desamparados) como "piso mínimo normativo", ou seja, como direitos básicos. Trata-se, portanto de assegurar o piso vital mínimo como conteúdo objetivo de direitos humanos no Brasil ${ }^{25}$. Nesse sentido,

Os instrumentos de promoção do desenvolvimento devem atender os princípios norteadores do Direito e insculpidos na Constituição Federal, mas tendo-se em consideração os direitos fundamentais, ou mesmo aquele "mínimo vital" de que o cidadão necessita para viver com dignidade, é de se reconhecer a importância do desenvolvimento para a consecução desses objetivos ${ }^{26}$.

Daí não ser difícil concluir que assegurar concretamente no plano normativo constitucional os denominados direitos humanos, direitos entendidos como direitos da pessoa

\footnotetext{
${ }^{24}$ FIORILLO, Celso Antonio. O direito de antena em face do direito ambiental no Brasil. São Paulo: Saraiva, 2000, p. 7.

${ }^{25}$ Nesse sentido, ver: FIORILLO, Celso Antonio Pacheco. Curso de Direito Ambiental Brasileiro. 17.ed. São Paulo: Saraiva, 2017; FIORILLO, Celso Antonio Pacheco; FERREIRA, Renata Marques. Liberdade de expressão e direito de resposta na Sociedade da Informação. Rio de Janeiro: Lumen Juris, 2017; FIORILLO, Celso Antonio Pacheco. $O$ Direito de Antena em face do Direito Ambiental no Brasil. São Paulo: Saraiva 2000; FIORILLO, Celso Antonio Pacheco; FERREIRA, Renata Marques. Tutela Jurídica do Patrimônio Genético em face da Sociedade da Informação. Rio de Janeiro: Lumen Juris, 2016; FIORILLO, Celso Antonio Pacheco. O Marco Civil da Internet e o Meio Ambiente Digital na Sociedade da Informação. São Paulo: Saraiva, 2015; e FIORILLO, Celso Antonio Pacheco. Princípios constitucionais do direito da sociedade da informaç̧ão. São Paulo: Saraiva, 2014.

${ }^{26}$ Ishikawa, Lauro. O Direito ao Desenvolvimento como Concretizador do Princípio da Dignidade da Pessoa Humana. São Paulo, 2008. 147f. Dissertação (Mestrado em Direito) - Pontifícia Universidade Católica de São Paulo, São Paulo, 2008, p. 120.
}

Revista de Direito Brasileira | São Paulo, SP | v. 17 | n. 7 | p. 191 - 202 | Mai./Ago. 2017 
humana, é assegurar a efetividade do piso vital mínimo indicado no art. 6o da Constituição Federal de 1988.

\section{O PISO VITAL MÍNIMO COMO DIREITO HUMANO: O DIREITO AMBIENTAL CONSTITUCIONAL ASSEGURANDO A DIGNIDADE DA PESSOA HUMANA}

A Carta Magna Brasileira ao explicitar direitos sociais em proveito da dignidade da pessoa humana (Art. 6- combinado com o art. 1ㅜㅡ, inciso III da Carta Magna), ou seja, ao fixar concretamente um conjunto básico de direitos humanos como piso vital mínimo determinou um comportamento ativo por parte do Estado ao garantir aos cidadãos uma situação de certeza.

A análise dos direitos humanos indicados no art. 6- nos leva necessariamente a observar o destaque dado pela Carta Magna à vida humana não só como objeto de todos os direitos assegurados no art. 5o em face de sua necessária interpretação com fundamento nos arts. 1으 , inciso III e 6o mas também e particularmente em decorrência do que estabelece o art. 225 da Carta Magna, dispositivo que fixa os contornos do direito ambiental constitucional.

Tratar, portanto de direitos humanos no âmbito constitucional é assegurar também o direito ao uso dos bens essenciais à sadia qualidade de vida da pessoa humana conforme determinado pelo art. 225 da Constituição Federal.

Daí ser possível afirmar que assegurar o direito constitucional ao meio ambiente é assegurar direito humano fundamental, ou seja, assegurar o uso dos bens essenciais à sadia qualidade de vida da pessoa humana indicados no art. 6- da Constituição Federal de 1988, é assegurar a garantia de um piso vital mínimo estrutural para um Estado Democrático de Direito ${ }^{27}$.

\section{OS QUATRO SIGNIFICATIVOS ASPECTOS DO DIREITO AMBIENTAL CONSTITUCIONAL ASSEGURANDO A DIGNIDADE DA PESSOA HUMANA COMO DIREITOS HUMANOS BÁSICOS E SUA INTERPRETAÇÃO POR PARTE DO SUPREMO TRIBUNAL FEDERAL}

O direito constitucional do meio ambiente sempre teve quatro significativos aspectos que efetivamente traduziam o conceito amplo de direito ambiental constitucional por força de uma interpretação sistemática advinda dos argumentos anteriormente indicados. Destarte constata-se a existência do meio ambiente cultural, do meio ambiente artificial, do meio ambiente do trabalho e do meio ambiente natural, sendo relações jurídicas destinadas a assegurar direitos humanos em sede constitucional.

Esses argumentos acabaram sendo acatados pelo Supremo Tribunal Federal em face da histórica ADI 3540 que teve como Relator o Ministro Celso de Mello ${ }^{28}$.

\footnotetext{
${ }^{27}$ Vide, dentre outros FIORILLO, Celso Antonio Pacheco. Curso de Direito Ambiental Brasileiro. 17.ed. São Paulo: Saraiva, 2017; FIORILlO, Celso Antonio Pacheco. Princípios do direito processual ambiental - A defesa judicial do patrimônio genético, do meio ambiente cultural, do meio ambiente digital, do meio ambiente artificial, do meio ambiente do trabalho e do meio ambiente natural no Brasil. 6.ed. São Paulo: Saraiva, 2016; FIORILLO, Celso Antonio Pacheco; FERREIRA, Renata Marques. Saúde ambiental, sua natureza jurídica e seus reflexos no direito ambiental brasileiro. In: Celso Antonio Pacheco Fiorillo e Renata Marques Ferreira. (Org.). Direito Ambiental Contemporâneo. 1ed. São Paulo: Saraiva, 2015, v. 01, pp. 17-53.

28 “A atividade econômica não pode ser exercida em desarmonia com os princípios destinados a tornar efetiva a proteção ao meio ambiente. A incolumidade do meio ambiente não pode ser comprometida por interesses empresariais nem ficar dependente de motivações de índole meramente econômica, ainda mais se se tiver presente que a atividade econômica, considerada a disciplina constitucional que a rege, está subordinada, dentre outros princípios gerais, àquele que privilegia a 'defesa do meio ambiente' ( $\mathrm{CF}$, art. 170, VI), que traduz conceito amplo e abrangente das noções de meio ambiente natural, de meio ambiente cultural, de meio ambiente artificial (espaço urbano) e de meio ambiente laboral. Doutrina. Os instrumentos jurídicos de caráter legal e de natureza constitucional objetivam viabilizar a tutela efetiva do meio ambiente, para que não se alterem as propriedades e os atributos que lhe são inerentes, o que provocaria inaceitável comprometimento da saúde, segurança, cultura, trabalho e bem-estar da

Revista de Direito Brasileira | São Paulo, SP | v. 17 | n. 7 | p. 191 - 202 | Mai./Ago. 2017
} 
De qualquer forma no âmbito do que pretendemos desenvolver no presente trabalho ficou claramente destacada pelo Supremo Tribunal Federal a absoluta relação do direito ambiental constitucional como direito humano. Com efeito, o Ministro Celso de Mello, relator da matéria, teve a oportunidade de aduzir que:

Todos sabemos que os preceitos inscritos no art. 225 da Carta Política traduzem, na concreção de seu alcance, a consagração constitucional, em nosso sistema de direito positivo, de uma das mais expressivas prerrogativas asseguradas às formações sociais contemporâneas. Essa prerrogativa, que se qualifica por seu caráter de metaindividualidade, consiste no reconhecimento de que todos têm direito ao meio ambiente ecologicamente equilibrado. Trata-se, consoante já proclamou o Supremo Tribunal Federal (RTJ 158/205-206, Rel. Min. Celso de Mello), com apoio em douta lição expendida por CELSO LAFER ("A reconstrução dos Direitos Humanos, p.131/132, 1988, Companhia das Letras), de um típico direito de terceira geração (ou de novíssima dimensão), que assiste, de modo subjetivamente indeterminado, a todo o gênero humano, circunstancia essa que justifica a especial obrigação - que incumbe ao Estado e à própria coletividade (PAULO AFONSO LEME MACHADO, "Direito Ambiental Brasileiro", p.121/123, item n. 31, 13 $3^{\text {a }}$ edição, 2005, Malheiros) - de defendê-lo e de preserva-lo em benefício das presentes e futuras gerações, evitando-se, desse modo, que irrompam, no seio da comunhão social, os graves conflitos intergeracionais marcados pelo desrespeito ao dever de solidariedade na proteção da integridade desse bem essencial de uso comum de todos quantos compõem o grupo social.

Demonstrando fazer parte do processo de afirmação dos direitos humanos afirma claramente o Supremo Tribunal Federal, por meio do referido relator que:

Em realidade, Senhor Presidente, o direito a integridade do meio ambiente constitui prerrogativa jurídica de titularidade coletiva, refletindo, dentro do processo de afirmação dos direitos humanos, a expressão significativa de um poder deferido, não ao indivíduo identificado em sua singularidade, mas, num sentido verdadeiramente mais abrangente, atribuído à própria coletividade social. Assim, resta bem demonstrado que é exatamente dentro do processo de afirmação dos direitos humanos que o Supremo Tribunal Federal "traduz conceito amplo e abrangente das noções de meio ambiente natural, de meio ambiente cultural, de meio ambiente artificial (espaço urbano) e de meio ambiente laboral, consoante ressalta o magistério doutrinário (CELSO ANTONIO PACHECO FIORILLO, "Curso de Direito Ambiental Brasileiro", p.20/23, item n. 4, 6 a ed., 2005, Saraiva; JOSÉ AFONSO DA SILVA, "Direito Ambiental Constitucional", p.21/24. itens ns. 2 e 3, $4^{\text {a }}$ ed. $/ 2^{\mathrm{a}}$ tir., 2003, Malheiros; JOSÉ ROBERTO MARQUES, Meio Ambiente Urbano, p.42/54, item n. 42005, Forense Universitária, v.g)". 


\section{CONCLUSÃO}

O direito ambiental constitucional (meio ambiente cultural, meio ambiente artificial, meio ambiente do trabalho e meio ambiente natural) ao tratar, consoante já proclamou o Supremo Tribunal Federal com apoio em doutrina especializada de um típico direito de terceira geração (ou de novíssima dimensão), que assiste de modo subjetivamente indeterminado, a todo o gênero humano constitui prerrogativa jurídica de titularidade coletiva, refletindo, dentro do processo de afirmação dos direitos humanos, a expressão significativa de um poder deferido, não ao indivíduo identificado em sua singularidade, mas, num sentido verdadeiramente mais abrangente, atribuído à própria coletividade social. Assegurar, pois a efetividade do piso vital mínimo, como conteúdo normativo do direito ambiental constitucional é assegurar a efetividade dos direitos humanos no Brasil.

\section{REFERÊNCIAS BIBLIOGRÁFICAS}

ARISTÓTELES. A Política. São Paulo: Martin Claret, 2002.

BOBBIO, Norberto; MATTEUCCI, Nicola; PASQUINO, Gianfranco. Dicionário de Política. 13.ed. Volume 1. Brasília: Editora Universidade de Barsilia, 2010.

BOEHNER, Philotheus; GILSON, Etienne. História da Filosofia Cristã-Desde as Origens até Nicolau de Cusa. 6.ed. Petrópolis: Vozes, 1995.

CAENEGEM, R. C. van. Uma introdução histórica ao direito privado. São Paulo: Martins Fontes, 1995.

CRANSTON, Maurice. O que são direitos humanos?. São Paulo/Rio de Janeiro: Difel, 1979.

CHAUÍ, Marilena. Convite à Filosofia. 8.ed. São Paulo: Ática, 1997.

FIORILlO, Celso Antonio Pacheco. Curso de Direito Ambiental Brasileiro. 17.ed. São Paulo: Editora Saraiva, 2017.

. O Marco Civil da Internet e o Meio Ambiente Digital na Sociedade da Informação. São Paulo: Saraiva, 2015.

2014.

Princípios constitucionais do direito da sociedade da informação. São Paulo: Saraiva, . O Direito de Antena em face do Direito Ambiental no Brasil. São Paulo: Saraiva 2000.

FIORILLO, Celso Antonio Pacheco; FERREIRA, Renata Marques. Liberdade de expressão e direito de resposta na Sociedade da Informação. Rio de Janeiro: Lúmen Juris, 2017.

. Tutela Jurídica do Patrimônio Genético em face da Sociedade da Informação. Rio de Janeiro: Lumen Juris, 2016.

Saúde ambiental, sua natureza jurídica e seus reflexos no direito ambiental brasileiro. In:

Celso Antonio Pacheco Fiorillo e Renata Marques Ferreira. (Org.). Direito Ambiental Contemporâneo. 1ed. São Paulo: Saraiva, 2015, v. 01, pp. 17-53. 
HATTENHAUER, Hans. Conceptos fundamentales del derecho civil - Introducción históricodogmática. Barcelona: Ed. Ariel, 1987.

ISHIKAWA, Lauro. O Direito ao Desenvolvimento como Concretizador do Princípio da Dignidade da Pessoa Humana. São Paulo, 2008. 147f. Dissertação (Mestrado em Direito) Pontifícia Universidade Católica de São Paulo, São Paulo, 2008.

RIOUX, Jean-Pierre; SIRINELLI, Jean- François. Para uma história cultural. Lisboa: Editorial Estampa, 1998.

NERY, Rosa Maria Barreto Borriello de Andrade. Pessoa Natural: sujeito de direito. Tese de Doutorado apresentada na PUC/SP sob a orientação de Celso Antonio Pacheco Fiorillo, São Paulo, 1998.

PÉREZ-LUÑO, Antonio Enrique. Derechos Humanos, Estado de Derecho y Constitución. 2.ed. Madrid: Technos, 1999.

SILVEIRA, Vladmir Oliveira da; ROCASOLANO, Maria Mendez. Os direitos humanos: conceitos, significados e funções. São Paulo: Saraiva, 2010.

VOVELLE, Michel. A Revolução Francesa 1789-1799. 70.ed. Lisboa: Portugal, 2007.

WIEACKER, Franz. História do Direito Privado. 2.ed. Lisboa: Fundação Calouste Gulbenkian, 1967. 